\title{
Electronic cigarettes and cardiovascular health: what do we know so far?
}

This article was published in the following Dove Press journal:

Vascular Health and Risk Management

\author{
Andrea MacDonald \\ Holly R Middlekauff ${ }^{2}$ \\ 'Department of Medicine, David Geffen \\ School of Medicine at UCLA, Los \\ Angeles, CA, USA; ${ }^{2}$ Department of \\ Medicine, Division of Cardiology, David \\ Geffen School of Medicine at UCLA, Los \\ Angeles, CA, USA
}

\begin{abstract}
While tobacco cigarette (TC) smoking has continued to drop to all-time lows, the use of electronic cigarettes (ECs), introduced in the US in 2007, has been rising dramatically, especially among youth. In EC emissions, nicotine is the major biologically active element, while levels of carcinogens and harmful combustion products that typify TC smoke are very low or even undetectable. TCs cause cardiovascular harm by activation of inflammatory pathways and oxidative damage, leading to atherogenesis and thrombosis, as well as through sympathetic activation triggering ischemia and arrhythmia. While ECs are generally believed to be safer than TCs, there remain many uncertainties regarding the overall cardiovascular health effects of EC usage. In this review, we discuss the various components of EC smoke and review the potential mechanisms of cardiovascular injury caused by EC use. We also discuss the controversy regarding the increasing epidemic of youth EC use weighed against the use of ECs as a smoking-cessation aid.
\end{abstract}

Keywords: electronic cigarettes, cigarette smoking, cardiovascular disease, nicotine

\section{Introduction}

Tobacco cigarette (TC) smoking is the primary cause of preventable cardiovascular death in the US, and tobacco-use cessation has long been the focus of significant public health efforts. According to a Surgeon General report from 2014, rates of smoking in the US have reached historic lows. ${ }^{1}$ Concomitant with this decline in TC smoking, the use of electronic cigarettes (ECs), introduced in the US in 2007, has markedly increased, especially among young people. ${ }^{2}$ ECs are comprised of a battery that heats but does not burn a flavored liquid typically containing nicotine to form an aerosol that the user inhales by puffing on the device. As such, ECs are free of the typical combustion products of TCs, including harmful carbon monoxide and almost all carcinogens, and have been promoted as a safer alternative to TCs. A mixed body of evidence suggests that ECs may promote quitting attempts, and recent evidence supports the notion that they may aid in TC-smoking cessation as well. Although analysis of the constituents in EC emissions compared to TC emissions supports the concept that ECs would be expected to be less harmful to cardiovascular health, long-term outcome studies are lacking. Additionally, the possible benefit of ECs as a smoking-cessation aid must be balanced with their increased popularity among never-smokers, especially teens. In this review, we summarize what is known and what areas remain open for more research regarding the effects of ECs on cardiovascular health, and touch upon the debate about the public health implications of ECs.
Correspondence: Holly R Middlekauff Department of Medicine, Division of Cardiology, David Geffen School of Medicine at UCLA, A2-237 CHS, 650 Charles Young Drive South, Los Angeles, CA 90025 , USA

Tel +I 310 2066672

$\mathrm{Fax}+13102069133$

Email hmiddlekauff@mednet.ucla.edu 


\section{TC effects on cardiovascular disease}

Before discussing the current data reflecting the cardiovascular effects of ECs, it is important to review the known adverse effects of TC smoke and the similarities and differences in TC and EC emissions. The cardiovascular effects of TCs have been extensively studied and reviewed previously $^{1,3,4}$ (Figure 1). TCs produce accelerated atherosclerosis and cardiovascular disease through a number of mechanisms, including increased oxidative stress and promotion of a proinflammatory state, leading to both lipid oxidation and thrombogenesis. ${ }^{5,6}$ TCs also increase catecholamine release and activation of the sympathetic nervous system, contributing to ischemia and arrhythmia risk. ${ }^{7}$ Through these mechanisms, TC smoking is associated with acute myocardial infarction (MI) and stent rethrombosis, both atrial and ventricular arrhythmias, and sudden death. ${ }^{5-7}$

\section{Nicotine vs other components of TCs and ECs}

Regarding the aforementioned adverse cardiovascular effects of TCs, the relative contributions of nicotine versus nonnicotine components of TC smoke are unknown. This is an important distinction, since nicotine is the most biologically active agent dispensed by ECs, and nonnicotine toxicants in EC emissions are present in much lower concentrations, if present at all, than TCs. One approach to answer this question comes from studies of nicotine-replacement therapy (NRT) and smokeless tobacco (ST) products, in which the nonnicotine combustion components are absent.

\section{Nicotine-replacement therapy}

Several short-term studies on the safety of NRT have been published. An early trial published in 1996 evaluated 584 patients with known cardiovascular disease who were randomized to a 10-week course of transdermal nicotine versus placebo. Cardiac end points in this study were cardiac arrest, MI, or admission to hospital for symptomatic angina, arrhythmia, or heart failure. NRT was not associated with an increase in any of these outcomes compared to placebo, a finding corroborated by other early studies. ${ }^{8,9}$ More recent meta-analyses showed elevated risk of cardiovascular events with NRT compared to placebo, though this difference was largely due to less serious events. NRTs did not increase risk of serious cardiovascular events, such as MI or sudden death. ${ }^{10} \mathrm{~A}$
2013 Cochrane review also reaffirmed that NRTs, often in combination with other smoking-cessation therapies, do increase success of quitting attempts. ${ }^{11}$ The long-term contributions of NRTs to cardiovascular sequelae have not been studied, and remain unknown.

\section{Smokeless tobacco}

Many of the conclusions regarding the safety of ST come from Sweden, where a form of ST called "snus" is used heavily by a large portion of the population. A review of ST studies can be found in Table 1. Note that this is not an exhaustive list, as this topic has been previously reviewed. ${ }^{12}$ In brief, early studies led to the conclusion that ST use was not associated with increased cardiovascular risk. ${ }^{13-16}$ However, a growing body of studies have shown ST use is associated with increased risk of cardiovascular events, ${ }^{17-19}$ including a recent meta-analysis of eleven studies. ${ }^{20}$ Further, in a large international study it was shown that ST use was associated with increased odds of MI compared to no tobacco use, with duo ST and TC use conferring higher risk than using either product individually. ${ }^{21}$ Additionally, it has been shown that cardiovascular mortality among snus users who quit after MI was cut in half compared to those who continued using snus after MI. ${ }^{22}$ The lack of consensus in the conclusions from ST studies is likely due to the wide variety of patterns of use and the differences in purity of ST products in different populations. The general consensus from these data is that ST likely confers an elevated cardiovascular risk, but not as high as would be expected from tobacco smoking. Note that these ST studies do not directly translate to EC risk, given that the method of delivery and rate of absorption of nicotine delivered by ST compared to ECs differs greatly and the nonnicotine components delivered by each method also differ between ST and ECs. In summary, on the continuum of nicotine-containing products, pure nicotine in NRT is likely the safest option compared with (in increasing order of harm) ST, ECs, and TCs. ${ }^{4}$

\section{Electronic cigarette aerosol: components}

Emissions from ECs, generated from heating liquids consisting of water, flavoring, solvents (propylene glycol and vegetable glycerin), and nicotine, include nicotine and nonnicotine components. Overall, nicotine is the most studied bioactive component in EC emissions, with the effects of the remaining components being ripe for study. 


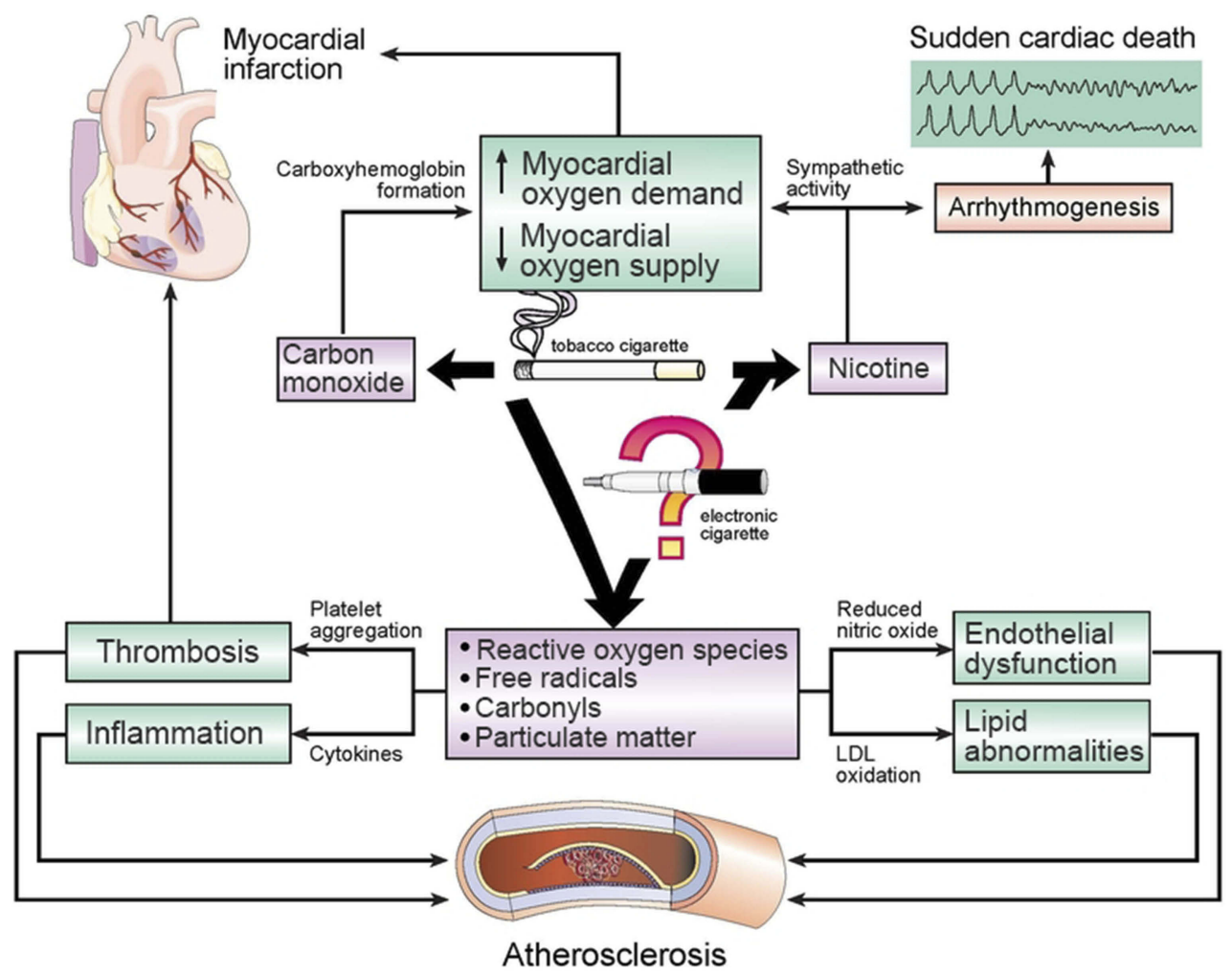

Figure I Effects of tobacco-cigarette smoke on cardiovascular disease.

Notes: Carbon monoxide, nicotine, free radicals, carbonyls (including acrolein), and particulate matter are known components of tobacco-cigarette smoke that contribute to cardiovascular disease. Electronic cigarettes do not emit carbon monoxide, but still deliver nicotine, and often (but not always) detectable levels of these other components, making their cardiovascular risk less clear.

\section{Nicotine}

As mentioned previously, the most important physiological effect of nicotine is sympathetic activation, and the most illuminating studies separating nicotine effects on cardiovascular health from those of other TC components have been included in the forerunning discussion of NRT and ST studies. Plasma-nicotine levels following EC use depend on the generation of the EC device: devices include first-generation "cig-alikes", second-generation "tanks", third-generation "mods", and fourth-generation "mod pods" (which include the popular USB-like devices). These later-generation devices deliver nicotine more efficiently and achieve higher plasma-nicotine levels than earlier devices. Nicotine delivery by ECs has been noted to be slower compared to nicotine delivery by TCs, although with the advent of nicotine salts delivered in the mod pods, this may no longer be true. ${ }^{25,26} \mathrm{In}$ 2015, the market saw the introduction of the Juul, a mod-pod EC device that uses nicotine salts rather than alkalinized nicotine, producing more efficient delivery of nicotine, with a time course approaching that of TCs. Nicotine content in the e-liquid, and the experience and topography of the EC user also determine nicotine-plasma levels..$^{5,23,24}$

\section{Solvents}

As detailed in previous reviews, ${ }^{5,6}$ the primary toxicants in emissions from ECs are acrolein, formaldehyde, and acetaldehyde. These are generated in higher amounts when ECs are used at higher power. It has been suggested that the taste at higher temperatures may be unpleasant, ${ }^{26}$ discouraging use at these high levels. Studies have shown lower urine levels of acrolein in EC users compared to TC smokers, despite similar EC and TC use, as indicated by similar urinary cotinine levels. ${ }^{6}$ In animal models, acrolein inhalation has been associated with autonomic imbalance predisposing to arrhythmias and vascular injury leading to increased risk of thrombosis and atherosclerosis. Acrolein has been implicated in myocardial dysfunction and cardiomyopathy. ${ }^{6}$ Less work has been done in humans, but an association has been reported between acrolein metabolites and platelet-leukocyte aggregates, ${ }^{6}$ supporting the notion of thrombogenic effect in humans. Similar results concerning autonomic dysregulation and oxidative damage have been seen in preclinical studies of aldehyde exposure. ${ }^{6}$ 


\begin{tabular}{|c|c|c|c|c|c|}
\hline 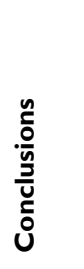 & 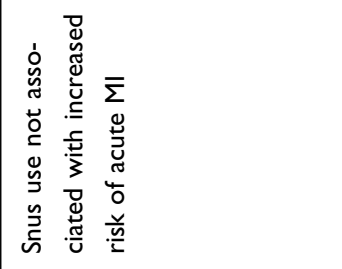 & 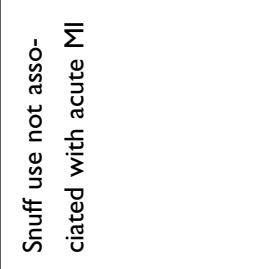 & 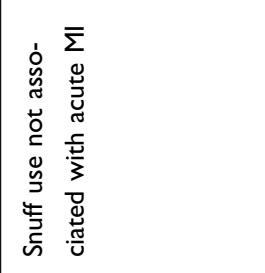 & 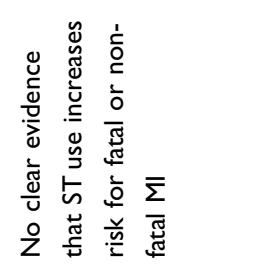 & 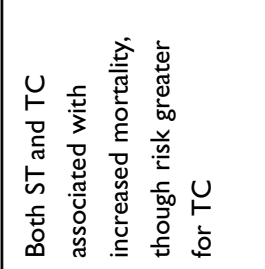 \\
\hline$\frac{n}{\vec{n}}$ & 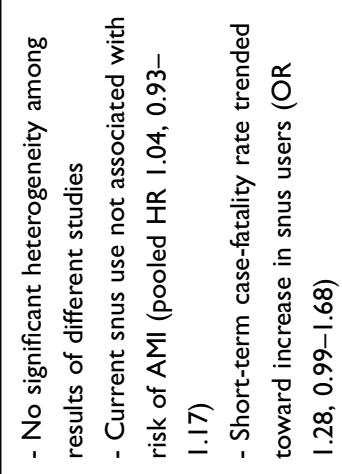 & 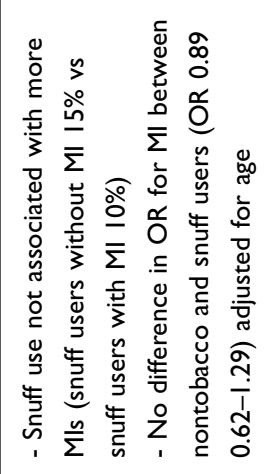 & 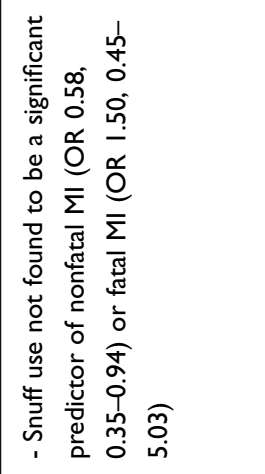 & 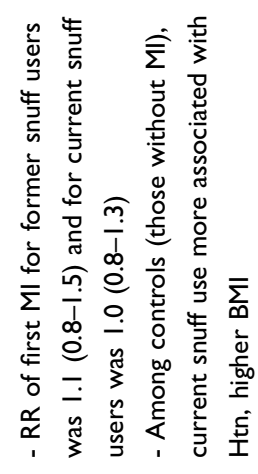 & 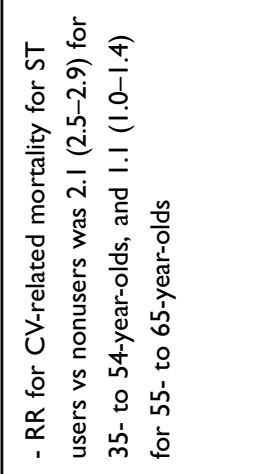 \\
\hline 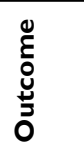 & 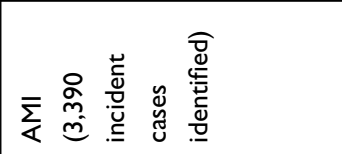 & $\sum_{<}$ & 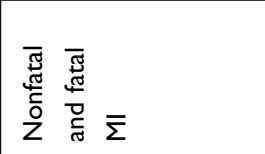 & 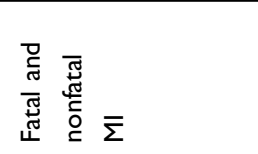 & 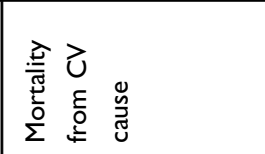 \\
\hline 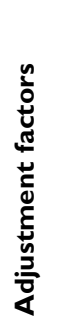 & 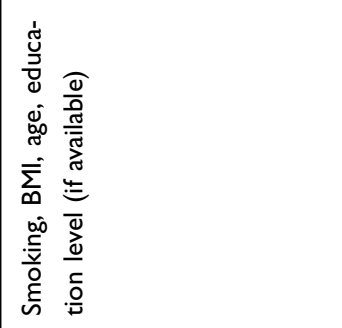 & 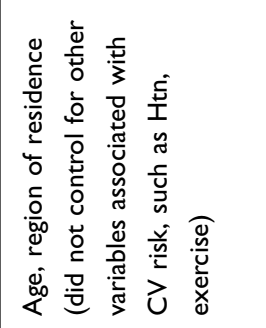 & 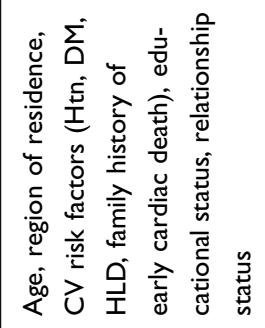 & 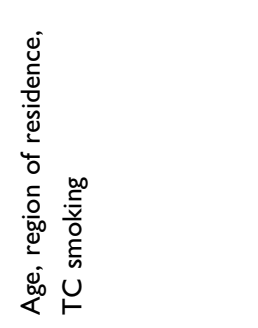 & 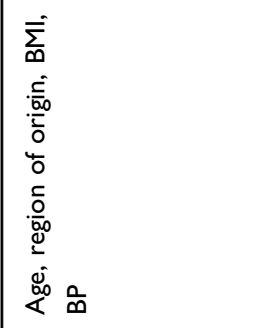 \\
\hline 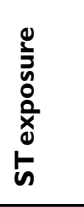 & 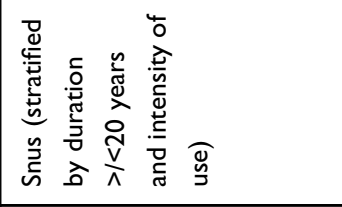 & 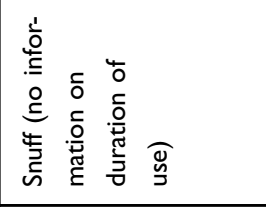 & 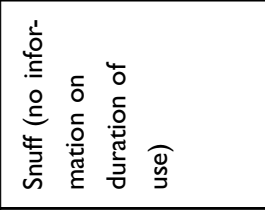 & $\stackrel{n}{\underline{n}}$ & \begin{tabular}{|l}
$\frac{0}{2}$ \\
$\frac{0}{2}$ \\
$\frac{\pi}{5}$ \\
$>$
\end{tabular} \\
\hline 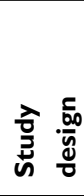 & 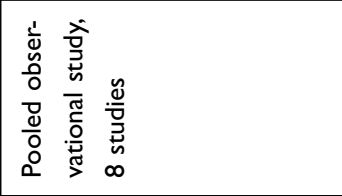 & 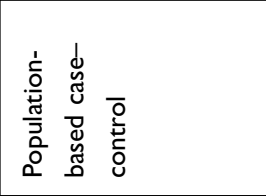 & 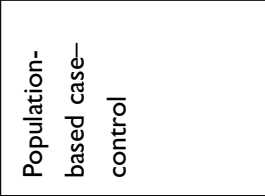 & 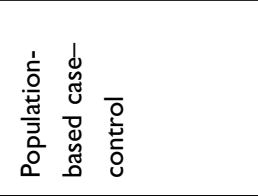 & $\begin{array}{l}\frac{\pi}{0} \\
\frac{0}{0} \\
ن\end{array}$ \\
\hline 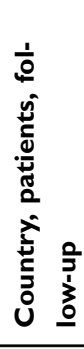 & 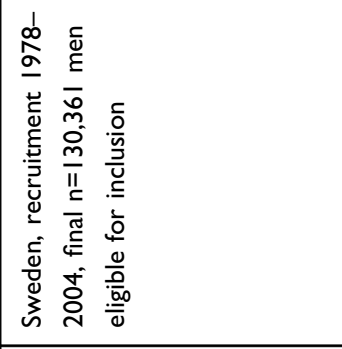 & 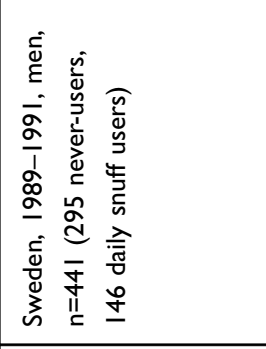 & 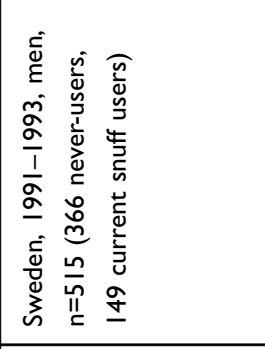 & 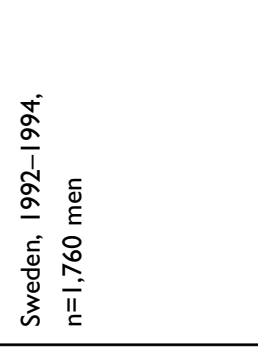 & 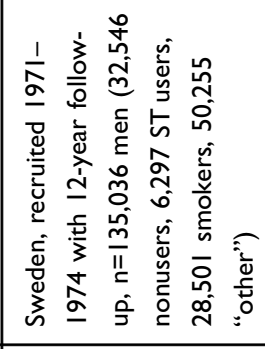 \\
\hline 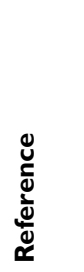 & 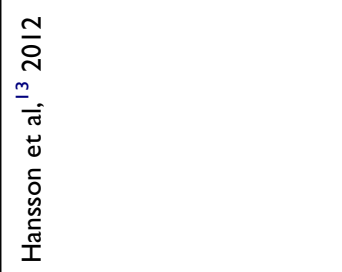 & 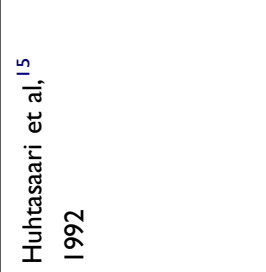 & 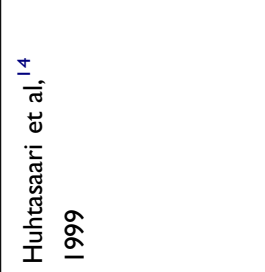 & 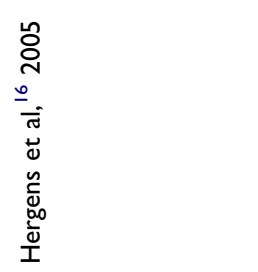 & 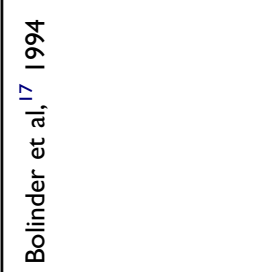 \\
\hline
\end{tabular}




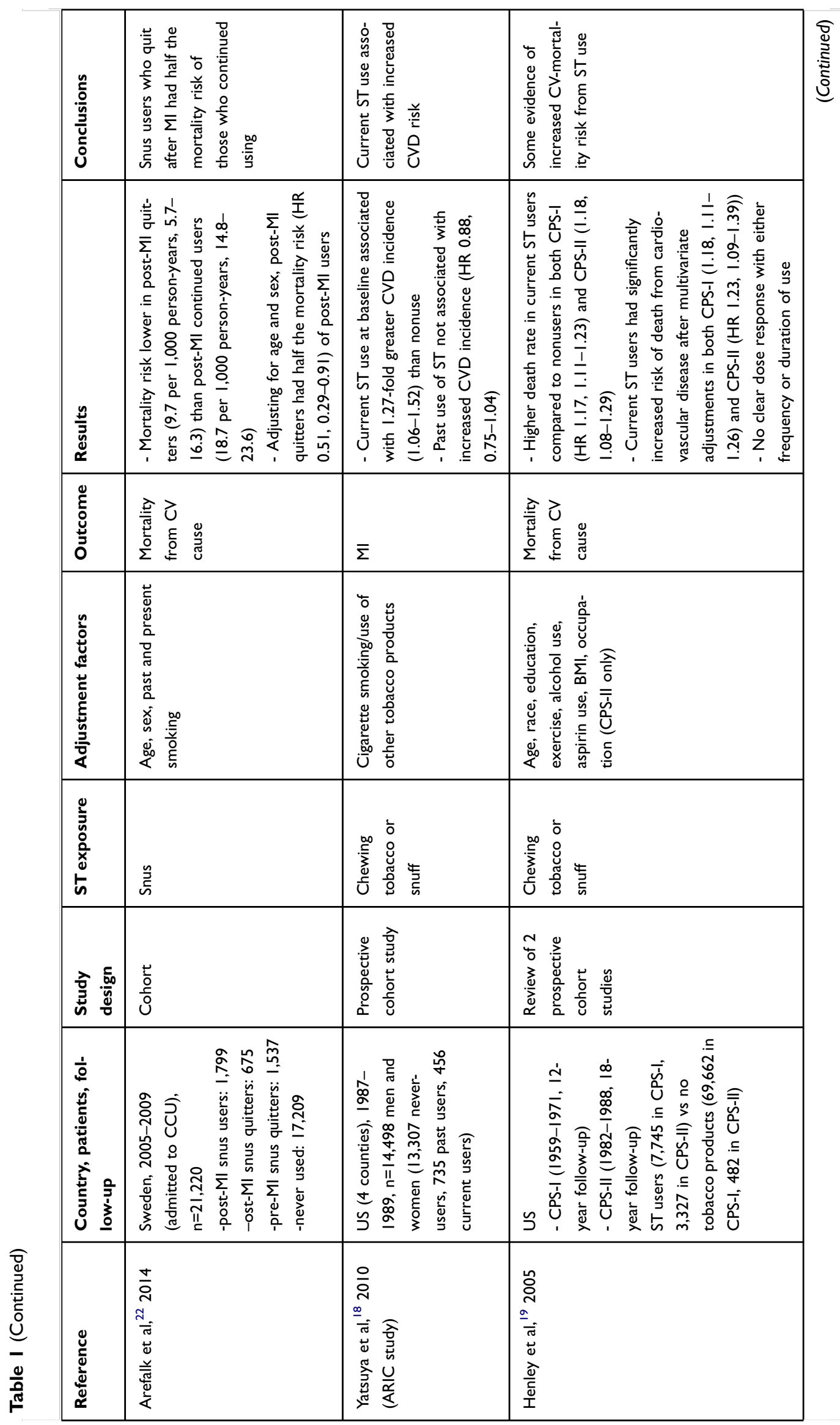




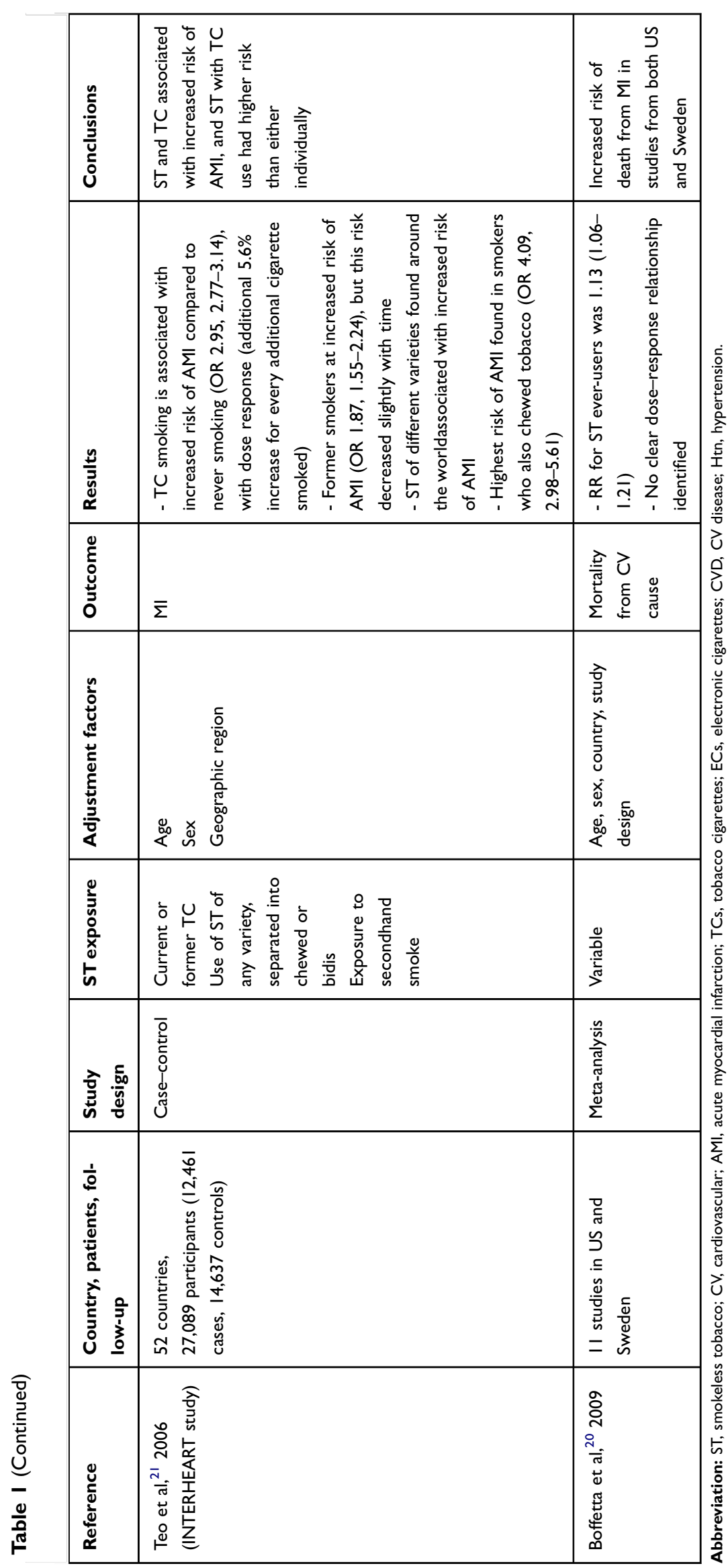




\section{Flavorings}

There are over 7,000 EC flavorings available, some of which contain known toxic chemicals, ${ }^{5}$ but there is no empirical evidence about the effects of these compounds on cardiovascular health.

\section{Free radicals and particulate matter}

Goel et al reported that the level of free radicals, both shortand long-lived, in EC emissions is at least ten times that of air pollution alone, though this is significantly lower than in TC smoke. ${ }^{27}$ These free radicals can be generated from any components in EC emissions, from flavorings to solvents, and likely increase cardiovascular risk. Additionally, ECs appear to produce the same small particles, approximately $2.5 \mu \mathrm{m}$ in size, as seen with TCs, though exact amounts vary with different liquids and puff topography. ${ }^{6}$ It has been proposed that these small particles have multiple, as yet undefined, adverse cardiovascular effects, including increased platelet aggregation. More important than particulate size is their constituents. Again, toxicants in EC emissions are orders of magnitude lower than in TC smoke.

\section{Metals}

Metals have been detected in emissions from ECs, presumably generated by heating of the metal coils in the device. The cardiovascular risks posed by these metal contaminants is undefined and unknown.

\section{Carbon monoxide}

Carbon monoxide, generated by TCs, is not present in EC emissions.

\section{Electronic cigarette effects on cardiovascular health}

TCs contribute to cardiovascular disease by promotion of inflammatory and oxidative pathways, promoting thrombogenesis and atherosclerosis, as well as through sympathomimetic pathways, resulting in autonomic and hemodynamic changes (Figure 1). Several small trials have addressed these mechanisms with regard to ECs in attempts to understand the effects of ECs on cardiovascular health.

\section{Electronic cigarettes and oxidative stress and inflammation}

Atherosclerosis is now recognized to be an inflammatory disease characterized by activation of the hematopoietic system, leading to inflammatory monocyte infiltration of the vasculature, in a process termed the splenocardiac axis. ${ }^{28}$ Activation of the splenocardiac axis is associated with elevated cardiac risk. We quantified inflammation using ${ }^{18}$ fluorodeoxyglucose positron-emission tomography in 31 participants (TC smokers, EC users, and nonsmokers) in hematopoietic and vascular tissues, components of the splenocardiac axis, and found increased inflammation in TC smokers compared to EC users, which was higher than in nonusers. ${ }^{29} \mathrm{TC}$ smoking leads to oxidative damage and systemic inflammation, both of which contribute to subsequent inflammatory atherosclerosis. Quitting TC smoking has been shown to return these inflammatory processes to levels comparable to those of nonsmokers. ${ }^{30}$ Vardavas et al published data confirming short-term inflammatory reactions in the pulmonary system with EC use, ${ }^{31}$ and significant additional work has shown persistent inflammation in the lungs with EC use. ${ }^{32}$ This implies there are likely inflammatory changes in other systems as well, including the cardiovascular system, but they have been less extensively studied. One study evaluated the presence of circulating white blood cells in 15 smokers and 15 nonsmokers at 1 hour after using a TC or an EC, in a crossover study. ${ }^{33}$ They found that both active TC smoking and passive exposure to TC smoke in the nonsmoking group was associated with increased white blood-cell count at 1 hour, whereas active and passive exposure to EC emissions was not. In summary, these studies demonstrated increased inflammation following both TC and EC use, though of larger magnitude with TC use.

Oxidative stress has been evaluated in a number of studies as well. First, in a single-blind crossover study of 40 subjects, Carnevale et al sought to assess oxidative stress and endothelial dysfunction in smokers and nonsmokers after exposure of both groups to both TCs and ECs. ${ }^{34}$ They reported that exposure to either TC or EC emissions significantly increased oxidative markers, but that the increase in oxidative markers was notably less pronounced after EC exposure than $\mathrm{TC}$ exposure. In a cross-sectional case-control study of 42 participants, EC users, and nonusers, we measured three parameters of oxidative stress: low-density lipoprotein (LDL) oxidizability, high-density-lipoprotein antioxidant/anti-inflammatory capacity, and paraoxonase 1 activity. ${ }^{35}$ We found that LDL oxidizability was significantly increased in chronic EC users compared to nonusers, indicative of increased risk of oxidative damage and oxidation of LDL predisposing to atherosclerosis. 
In summary, these studies are consistent with the concept that ECs do increase inflammation and oxidative stress, with potential predisposition to atherosclerosis. However, this oxidative stress appears to be greater in TC smokers than EC users, a distinction that requires further study and is important when drawing public health conclusions regarding ECs.

\section{Electronic cigarettes and vascular health}

The effect of ECs on vascular health has been studied through evaluation of biomarkers, including brachial artery flow-mediated dilatation (FMD), circulating endothelial progenitor cells (EPCs), and pulse-wave velocity (PWV), a surrogate for arterial stiffness. FMD is a test of endothelial function, and abnormal FMD is a risk factor for future cardiovascular events. Abnormal FMD is present in TC smokers, and even nonsmokers exposed to secondhand smoke. Carnevale et al reported a decrease in FMD after acute exposure to either TCs or ECs in a crossover study, although the decline in FMD was significantly less severe following EC use compared to TC smoking. ${ }^{34}$ Another study has suggested that FMD may be affected by an interaction with oral contraceptive use, ${ }^{36}$ though this requires further confirmation in additional studies. Increased numbers of circulating EPCs have been proposed to be a marker for cardiovascular disease risk; however, it has also been seen that nicotine itself can stimulate EPC release in the absence of endothelial injury, and the exact implications of this finding on cardiovascular health are unclear. ${ }^{5,37} \mathrm{~A}$ crossover study of the effect of acute EC use compared to TC smoking on circulating EPCs in 16 healthy subjects revealed an increase in EPCs after EC exposure qualitatively similar to the magnitude of EPC increase after TC smoking. ${ }^{38}$ Notably, no nicotine-free control was used in this study, making it difficult to assess what component in EC emissions is responsible for this effect. ${ }^{37}$ Chaumont et al measured microvascular function in humans, and showed impaired NO-induced vasodilation and increased oxidative stress after exposure to ECs with nicotine, but not after exposure to EC without nicotine or sham-EC use. ${ }^{39}$ This would support the concept that the oxidative and endothelial stresses may be related to nicotine itself.

In an acute crossover study, Vlachpoulos et al explored the effect of acute EC use versus TC smoking on arterial stiffness measured by PWV in 24 chronic TC smokers. PWV has been shown to be an independent risk factor for adverse cardiovascular events. ${ }^{40}$ No significant difference in PWV following EC use or TC smoking was uncovered. $^{25}$ In contrast, a study of 15 healthy women reported a statistically significant increase in stiffness index based on PWV after smoking a TC but not after an EC. ${ }^{41}$ A third study subsequently showed increased PWV after using ECs with nicotine, but not in ECs without nicotine or an empty EC (control), thereby attributing the changes specifically to nicotine instead of other components of ECs. ${ }^{39}$ These three studies were limited by small samples, which may have contributed to the incongruous data. It is additionally worth noting that all of these studies measured vascular changes only in the short term, hours after EC or TC use.

In summary, the available data are concerning for adverse vascular effects of acute EC use, which may be less severe than acute TC smoking and attributable to the nicotine in EC emissions. Larger-scale studies of chronic EC users are not available, but would be illuminating.

\section{Electronic cigarettes and thrombogenesis}

TCs are known to be associated with platelet aggregation and thrombogenesis. In an in vitro study evaluating platelet function, incubated platelets with TC-smoke extract, EC-smoke extract, and pure nicotine, platelet aggregation was enhanced and adhesion receptors upregulated after incubation with both EC- and TC-smoke extract, regardless of nicotine or exposure duration. ${ }^{42}$ The first in vivo crossover study of platelet responses to acute TC and EC use in humans showed an increase in platelet aggregation in TC smokers and nonsmokers after smoking either an EC or TC, though the increase was significantly less after EC use than TC smoking in both groups. ${ }^{43}$ A small randomized controlled trial (RCT) of 20 participants compared two markers of platelet activation - CD40L and P-selectin - after use of ECs versus TCs. They found that traditional TCs increased these markers significantly more than traditional ECs. ${ }^{44}$

In summary, limited data support the notion that acute EC use increases platelet aggregation, a risk factor for adverse cardiovascular events. This increased platelet aggregation is significantly lower after EC use than TC use.

\section{Electronic cigarettes and hemodynamics}

A major portion of studies evaluating cardiovascular effects of EC have studied hemodynamic parameters, predominantly heart rate (HR) and blood pressure (BP). It is known that nicotine exposure acutely causes release of 
catecholamines, leading to increased BP and HR within 510 minutes, but that this effect then stabilizes and declines, even while nicotine levels continue to increase. ${ }^{7}$ The overall trend in EC studies shows that TC smoking acutely increases BP more than EC smoking, but that both are higher than baseline BPs. The studies were small, and notably this trend is consistent with the expected effects of nicotine. The studies are summarized in Table $2 .^{25,41,45-47}$ There have been few studies evaluating whether or not these acute changes in BP and HR have clinical relevance for long-term risk. Farsalinos et al showed that there was a significant reduction in BP with smoking reduction or cessation in smokers who had elevated BP at baseline ${ }^{47}$ in a trial evaluating ECs as a cessation tool.

In summary, the majority of studies on EC used measured only acute, transient changes in BP and HR, and there have been few studies investigating long-term effects of ECs on hemodynamics. Further, the hemodynamic effects of ECs and TCs are small, and of unclear and unproven clinical significance.

Only one study has attempted to investigate the acute effect of ECs on myocardial function. ${ }^{48}$ The study consisted of 81 healthy heavy TC smokers compared to healthy ex-TC smokers using comparable concentrations of ECs for at least 1 month. They abstained from smoking for 4 hours, underwent echocardiography, and then smoked one TC or used an EC for 7 minutes (approximate time to smoke one TC), followed by repeat echocardiography. The researchers found no change in left ventricular function after EC use, but changes in diastolic function after just one TC. This study was limited by its small sample, and notably did not measure plasma-nicotine levels. Its conclusions also may not apply to unhealthy smokers, such as those with known coronary disease.

Overall, these findings imply that ECs do not have the same negative effects on myocardial function as TCs do, but there are significant limitations in the study.

\section{Electronic cigarettes and arrhythmogenesis}

TCs are known to be arrhythmogenic, associated with both atrial and ventricular arrhythmias and sudden cardiac death. One mechanism by which TC smoking is proposed to be proarrhythmic is by increasing sympathetic nerve activity. In a case-control study of $42 \mathrm{EC}$ users and nonusers in our lab, we measured HR variability (HRV) to determine if ECs also produced a shift toward a hyperadrenergic state. ${ }^{35} \mathrm{We}$ showed that habitual EC users had similar abnormal patterns of HRV as reported in TC users, consistent with activation of the sympathetic nervous system. This pattern has been associated with increased MI and sudden-death risk in patients with known cardiovascular disease, as well as those without known cardiovascular disease. In a followup crossover study, we measured HRV in nonsmokers before and after they used an EC with nicotine, an EC without nicotine, and an empty EC (sham control) at three time points separated by a 4 -week washout. ${ }^{49}$ We found that only using the EC with nicotine, not the EC without nicotine or the sham control, led to increased cardiac sympathetic nerve activity and change in HRV consistent with increased cardiovascular risk.

In summary, chronic EC users have the same adverse HRV profile associated with increased cardiovascular risk seen in patients with and without known cardiac disease. Furthermore, nicotine, not nonnicotine constituents, in EC emissions contribute to acute abnormalities in HRV.

\section{Electronic cigarette population studies}

Only one large cross-sectional study has been published examining the association between chronic EC use and incidence of MI. ${ }^{50}$ Alzahrani et al used data from the National Health Interview Surveys of 2014 and 2016, each with $>30,000$ patients, to examine associations between EC use and MI. They classified subjects into self-reported groups of never, former, some days, and daily EC users and used logistic regression to control for other cardiac risk factors. They reported significantly increased risk (OR 1.79) for daily EC users of having MI. However, this cross-sectional study did not delineate the temporal relationship between EC use and MI, and many current EC users are former TC users. Therefore, a patient who had an MI while a TC smoker and subsequently switched to ECs may be misclassified as an EC user with an MI by this survey. ${ }^{51}$ Long-term, longitudinal studies are lacking, but are necessary to determine the lasting impact of EC use on cardiovascular risk.

\section{Electronic cigarettes as a smoking- cessation strategy}

Although many adults use ECs to quit TC smoking, ${ }^{52,53}$ the question remains: Do ECs help facilitate smoking cessation? A number of observational studies have addressed the question, though there have only been four 


\begin{tabular}{|c|c|c|c|c|c|}
\hline 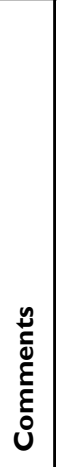 & 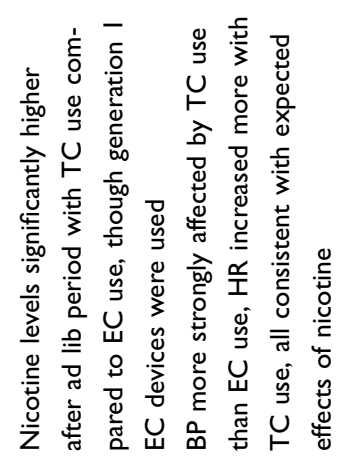 & 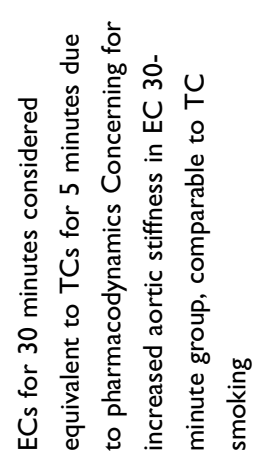 & 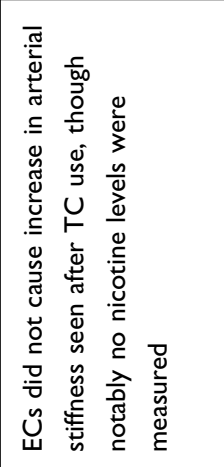 & 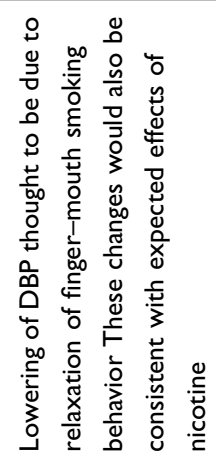 & 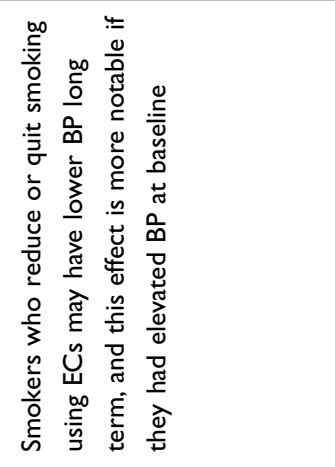 \\
\hline $\begin{array}{l}\frac{y}{\underline{y}} \\
\bar{y} \\
\tilde{x}\end{array}$ & 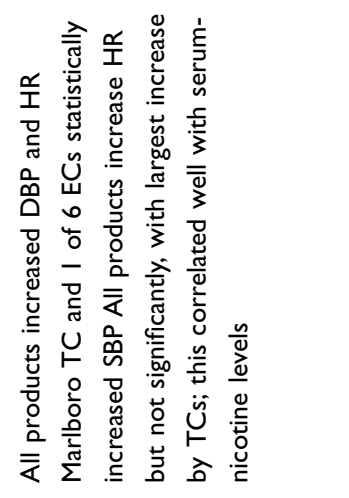 & 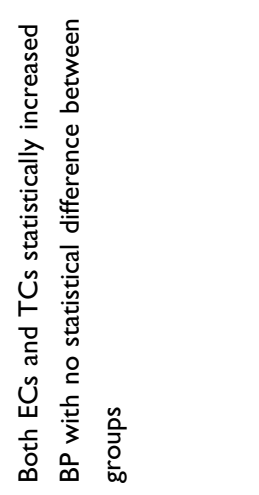 & 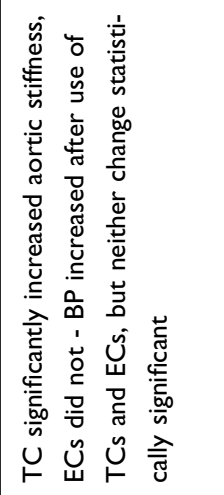 & 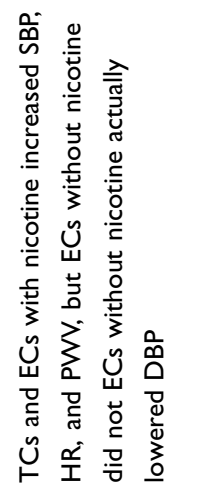 & 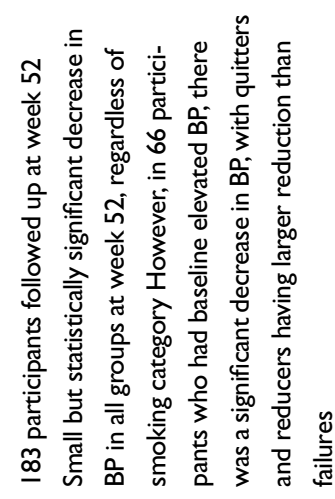 \\
\hline 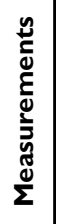 & 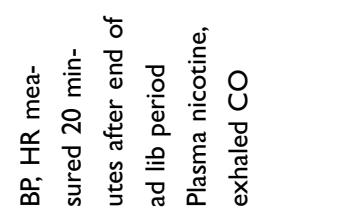 & 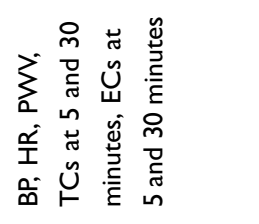 & 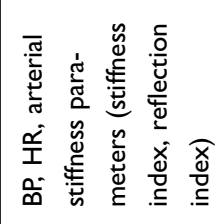 & 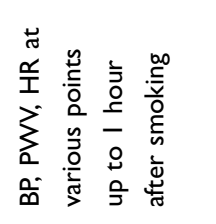 & $\begin{array}{l}\frac{\alpha}{I} \\
\stackrel{\alpha}{\infty}\end{array}$ \\
\hline $\begin{array}{l}0 \\
\frac{n}{3} \\
0 \\
0\end{array}$ & 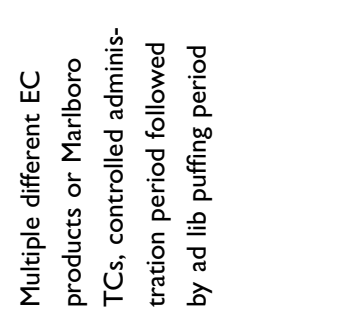 & 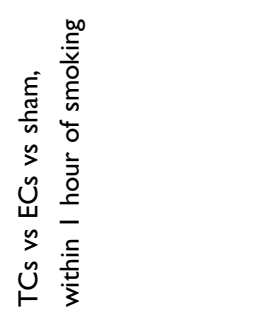 & 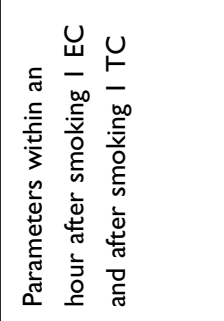 & 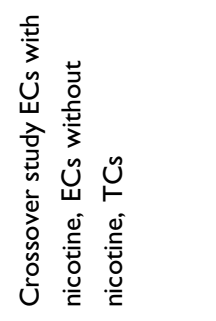 & 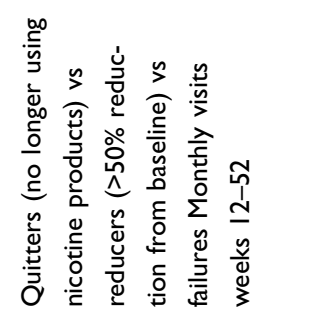 \\
\hline 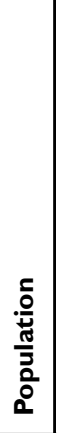 & 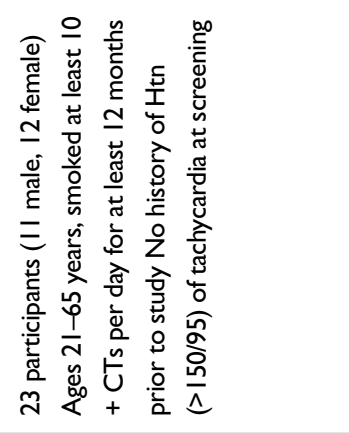 & 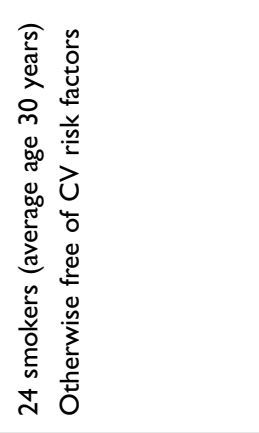 & 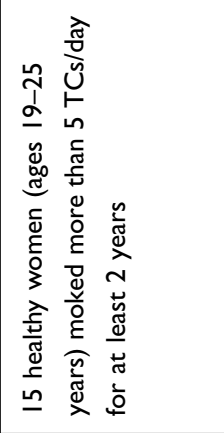 & 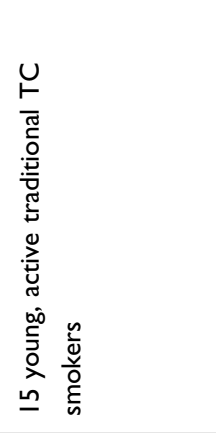 & 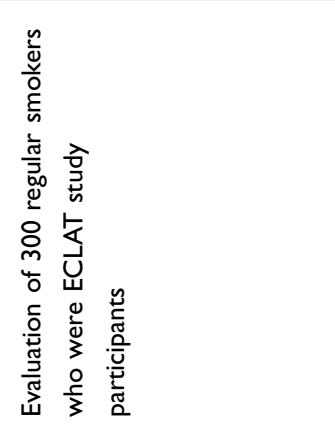 \\
\hline 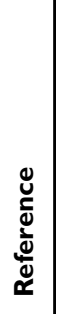 & 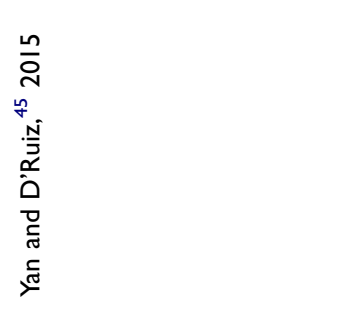 & 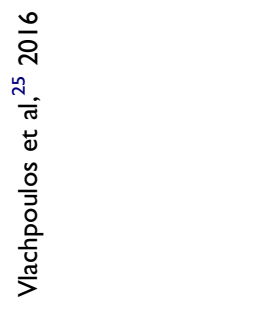 & 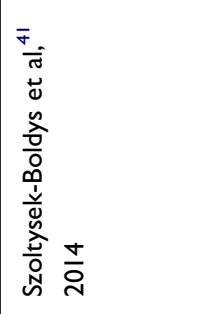 & 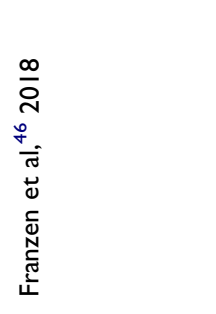 & 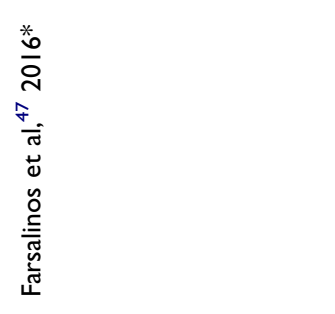 \\
\hline
\end{tabular}




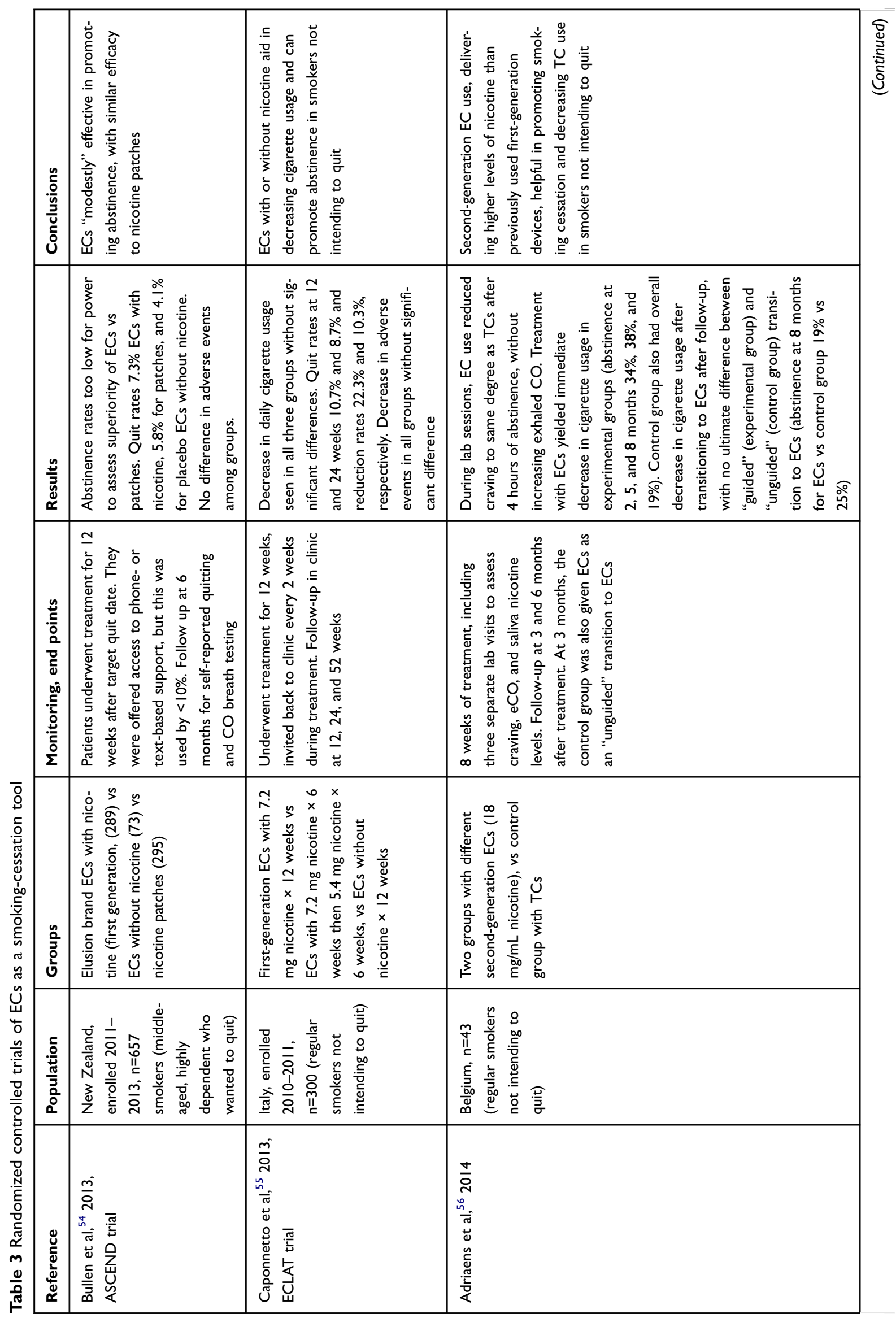




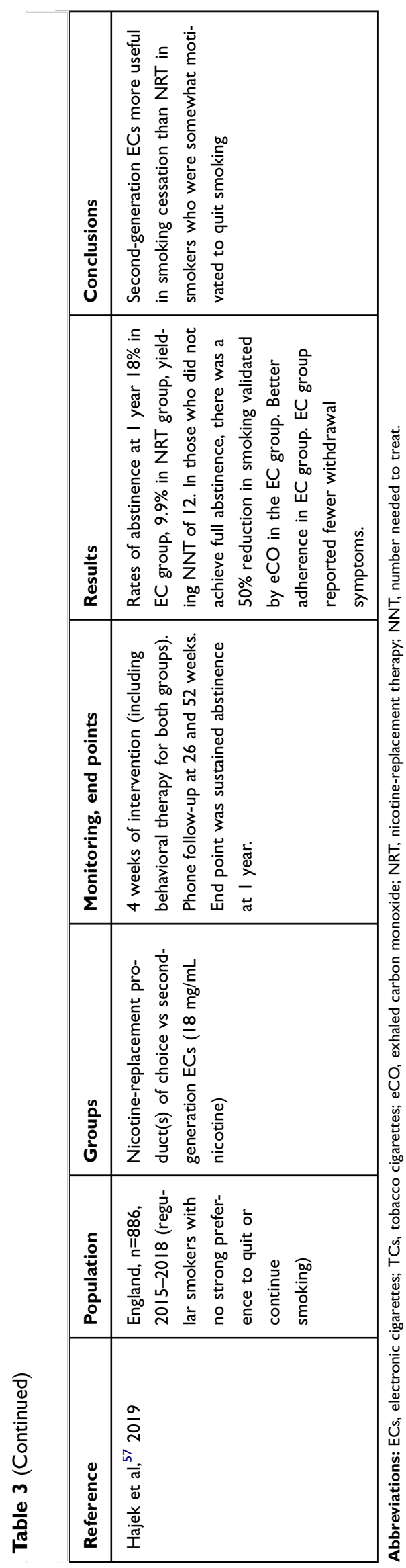

RCTs. ${ }^{54-57}$ Evidence from the RCTs, which are summarized in Table 3, are limited by study design, study size, and duration of follow-up. The first three RCTs were analyzed in a 2016 Cochrane review, which concluded with low confidence that long-term use of ECs was associated with marginally increased quitting rates compared to placebo. ${ }^{58}$ In this vein, Beard et al reported that increased prevalence of EC use in England has been positively associated with success rate of quitting attempts. ${ }^{59}$ In early 2019, the largest of these RCTs was published, showing that ECs were significantly more effective, in fact twice as effective at 1 year, in smoking cessation compared to NRTs. ${ }^{57}$ In this study, there was high adherence to the EC regimen, which the writers posited was partially related to the fact that the EC group reported fewer withdrawal symptoms. Of note, $80 \%$ of those that successfully quit TCs were still using ECs at 1 year. The authors did point out that their findings could not necessarily be generalized to those who start using ECs for purposes other than cessation or to those using first-generation EC devices.

While more recent RCT data give cause for optimism, observational studies have yielded mixed results, which have been reviewed elsewhere. ${ }^{60}$ Many have shown that daily EC use may be associated with more quitting attempts and fewer TCs smoked per day, but not necessarily with higher rates of cessation. ${ }^{61,62}$ It should be emphasized that decreasing the number of TCs smoked per day is not expected significantly to decrease cardiovascular risk, since there is a very steep TC dose-cardiovascular death relationship, and smoking one to three TCs a day poses similar cardiovascular risks as smoking one to three packs per day. ${ }^{63}$ Of concern, a meta-analysis by Kalkoran and Glantz ${ }^{64}$ further concluded that EC use to help quit TCs was paradoxically associated with even lower quitting rates than not using ECs in the cessation strategy, perhaps because ECs perpetuated nicotine addiction.

In summary, what limited RCT data we do have points to ECs being helpful in smoking cessation. It should be noted that these studies were largely "switch" trials, trading one nicotine-delivery system (TCs) for another (ECs). Given the lethality of TCs and the likelihood that ECs are less harmful, ECs may be a reasonable last-resort alternative to continued TC smoking if all other avenues have been exhausted. Concern over the long-term cardiovascular risks associated with lifelong nicotine use remain. 


\section{Electronic cigarettes: promises and perils}

The major promises of EC have been the hope that they will help with smoking cessation and that they may be a safer alternative to TCs. A major part of the ongoing debate about the health risks and benefits of ECs is the balance between their ability to aid in smoking cessation versus their popularity among youth and risk of smoking initiation in never-smokers. It is important to understand the epidemiology of EC use to understand this debate. The Action on Smoking and Health (ASH) survey in England showed that EC use continues to increase rapidly: from $700,000 \mathrm{EC}$ users in 2012 to 3.2 million users in $2018 .^{53}$ The majority of EC users are ex-smokers or dual users. ${ }^{53}$ A study from the University of Michigan used a dynamic model based on smoking-initiation and -cessation rates to predict life years saved versus lost by the year $2070 .{ }^{65}$ Even using conservative parameters, their overall conclusion was that ECs aiding smoking cessation outweighs the risk of EC-driven smoking initiation, a conclusion with significant public health implications. This finding has also been corroborated in youth, ${ }^{66}$ as is discussed herein.

\section{Electronic cigarette use among never tobacco cigarette-smoking youth: cause for concern}

Of great concern is the increased rate of EC use among youth. Recent data from the annual Monitoring the Future survey showed a $5.2 \%$ increase in use of any nicotine products among youth from 2017 to 2018, such that $28.9 \%$ of adolescents use at least one nicotine product. ${ }^{67}$ This increase has been entirely driven by EC use, or "vaping", as we have seen a 10\% increase in EC use and a decline in use of all other nicotine products. ${ }^{67}$ It is estimated that approximately one in five high school students and one in 20 middle school students currently use $\mathrm{ECs},{ }^{68}$ which is a $78 \%$ increase among high school-student and $48 \%$ increase among middle school-student EC use from 2017 to $2018 .{ }^{69}$ These findings were also corroborated by the National Youth Tobacco Survey by the Centers for Disease Control and Prevention in 2017, and represent the largest absolute increases in prevalence of EC use among adolescents ever recorded. ${ }^{67} \mathrm{EC}$ use is enabled by the fact that new products continue to populate the market, most recently the Juul, an EC device that looks like a flash drive and has become so popular that "to Juul" has become a colloquial term explored in papers such as the Washington Post and the New Yorker. This increased use of ECs among youth has been declared an epidemic by the Office of the Surgeon General ${ }^{68}$ and the FDA.

There is some debate as to whether EC use in youth increases future TC smoking. A 2018 National Academy of Science, Engineering, and Medicine report concluded that there was moderate evidence that EC use increases future TC smoking among youth and adults. ${ }^{70}$ However, more evidence looking at population trends has indicated that this effect is likely negligible, ${ }^{66}$ since TC smoking continues to decline in middle and high school children, although EC use is increasing. EC use appears to be a diversion from TCs, rather than a gateway to increased TC use. ${ }^{67}$ Given that we do not know the long-term health consequences, more aggressive regulation is needed to curb the rapidly expanding use of Juul and other EC devices among youth. This might include additional attention to new devices as they enter the market, restrictions on where ECs are sold, restricting flavors marketed to youth (especially candy flavorings, mint, and menthol), and stricter penalties - and their uniform enforcement - for selling ECs to youth.

In summary, although EC use may be safer than TCs, ECs are not harmless, as summarized by their adverse effects on cardiovascular biomarkers, including increased oxidative stress, inflammation, platelet aggregation, poor vascular health, and sympathetic activation. There is some evidence that they may help decrease TC smoking and that on a population level their benefit as a smoking aid may outweigh the danger of smoking initiation.

\section{Some difficulties of EC studies}

A number of challenges to designing EC studies are apparent in reviewing the current literature. First, the different brands and generations of ECs are extremely variable with regard to both nicotine delivery and aerosol. Therefore, it is difficult for studies to attain similar nicotine levels. In fact, one of the four RCTs evaluating smoking cessation proposed that their results may have differed from the previous two RCTs because they used a second-generation rather than a first-generation device. ${ }^{56}$ The next RCT also used second-generation devices, and results were more consistent with the former study. The different puffing habits of EC users may also contribute to the difficulty in attaining standard nicotine levels, and the majority of studies do not allow for ad lib puffing. Second, and as noted previously in the discussion of population studies, many current EC users are former TC users, and many are also dual users. Prospective studies to assess EC risk could thus be set 
up, but as pointed out by Benowitz and Burbank, the percentage of EC-only users who are of the age range when most cardiovascular events occur is small. ${ }^{3}$

\section{Conclusion}

aTo date, the effects of ECs on long-term cardiovascular health are inconclusive, but concerning. However, as reviewed here, the effects on biomarkers may portend increased cardiovascular risk, with multiple small in vivo and in vitro studies showing at least temporary increases in oxidative stress, inflammation, vascular dysfunction, and thrombogenic and sympathomimetic pathways (Figure 1). These effects are likely consistent with the properties of nicotine, though the effects of all of the components of EC emissions have not yet been completely elucidated. Though they may not be as harmless as previously proposed, it seems likely that on the spectrum of tobacco products, ECs are less harmful than TCs, and there is increasing evidence that ECs may help promote TC cessation. As such, ECs may be helpful for risk reduction in future. More longitudinal rather than cross-sectional studies are needed. Finally, given the concerns about increasing EC use among teens, tighter regulation of these products to limit availability, as well as regulation of the liquids and flavorings, are necessary moving forward.

\section{Abbreviation list}

EC, electronic cigarette; TC, tobacco cigarette; CVD, cardiovascular disease; PWV, pulse-wave velocity; ST, smokeless tobacco; NRT, nicotine-replacement therapy; MI, myocardial infarction; FMD, flow-mediated dilatation; EPC, endothelial progenitor cells; HRV, heart-rate variability.

\section{Disclosure}

Dr Middlekauff receives research support from the Tobacco-Related Diseases Research Program (25IR-0024, 28IR-0065). The authors report no other conflicts of interest in this work.

\section{References}

1. Alberg AJ, Shopland DR, Cummings KM. The 2014 Surgeon General's report: commemorating the 50th Anniversary of the 1964 Report of the Advisory Committee to the US Surgeon General and updating the evidence on the health consequences of cigarette smoking. Am J Epidemiol. 2014;179(4):403-412. doi: 10.1093/aje/kwt335

2. US Department of Health and Human Services. E-cigarette use among youth and young adults. A Report of the Surgeon General. Atlanta, GA: US Department of Health and Human Services, Centers for Disease Control and Prevention; 2016. Available from: https://e-cigar ettes.surgeongeneral.gov/documents/2016_SGR_Full_Report_non508.pdf. Accessed June 13, 2019.
3. Benowitz NL, Burbank AD. Cardiovascular toxicity of nicotine: implications for electronic cigarette use. Trends Cardiovasc Med. 2016;26(6):515-523. doi:10.1016/j.tcm.2016.03.001

4. Kalkhoran S, Benowitz NL, Rigotti NA. Prevention and treatment of tobacco use: JACC health promotion series. J Am Coll Cardiol. 2018;72(9):1030-1045. doi:10.1016/j.jacc.2018.06.036

5. Benowitz NL, Fraiman JB. Cardiovascular effects of electronic cigarettes. Nat Rev Cardiol. 2017;14(8):447-456. doi:10.1038/nrcardio.2017.36

6. Qasim H, Karim ZA, Rivera JO, Khasawneh FT, Alshbool FZ. Impact of electronic cigarettes on the cardiovascular system. $J \mathrm{Am}$ Heart Assoc. 2017;6(9). doi:10.1161/JAHA.117.006353

7. Middlekauff HR, Park J, Moheimani RS. Adverse effects of cigarette and noncigarette smoke exposure on the autonomic nervous system: mechanisms and implications for cardiovascular risk. $J \mathrm{Am}$ Coll Cardiol. 2014;64(16):1740-1750. doi:10.1016/j.jacc.2 014.06.1201

8. Joseph AM, Norman SM, Ferry LH, et al. The safety of transdermal nicotine as an aid to smoking cessation in patients with cardiac disease. N Engl J Med. 1996;335(24):1792-1798. doi:10.1056/ NEJM199612123352402

9. Working Group for the Study of Transdermal Nicotine in Patients with Coronary Artery Disease. Nicotine replacement therapy for patients with coronary artery disease. Arch Intern Med. 1994;154 (9):989-995.

10. Mills EJ, Thorlund K, Eapen S, Wu P, Prochaska JJ. Cardiovascular events associated with smoking cessation pharmacotherapies: a network meta-analysis. Circulation. 2014;129(1):28-41. doi:10.1161/ CIRCULATIONAHA.113.003961

11. Cahill K, Stevens S, Perera R, Lancaster T. Pharmacological interventions for smoking cessation: an overview and network meta-analysis. Cochrane Database Syst Rev. 2013;(5):CD009329.

12. Piano MR, Benowitz NL, Fitzgerald GA, et al. Impact of smokeless tobacco products on cardiovascular disease: implications for policy, prevention, and treatment: a policy statement from the American heart association. Circulation. 2010;122(15):1520-1544. doi:10.1161/CIR.0b013e3181f432c3

13. Hansson J, Galanti MR, Hergens MP, et al. Use of snus and acute myocardial infarction: pooled analysis of eight prospective observational studies. Eur J Epidemiol. 2012;27(10):771-779. doi:10.1007/ s10654-012-9704-8

14. Huhtasaari F, Lundberg V, Eliasson M, Janlert U, Asplund K. Smokeless tobacco as a possible risk factor for myocardial infarction: a population-based study in middle-aged men. $J \mathrm{Am}$ Coll Cardiol. 1999;34(6):1784-1790. doi:10.1016/S0735-1097 (99)00409-X

15. Huhtasaari F, Asplund K, Lundberg V, Stegmayr B, Wester PO. Tobacco and myocardial infarction: is snuff less dangerous than cigarettes? Bmj. 1992;305:1252-1256. doi:10.1136/bmj.305.68 64.1252

16. Hergens MP, Ahlbom A, Andersson T, Pershagen G. Swedish moist snuff and myocardial infarction among men. Epidemiology. 2005;16 (1):12-16.

17. Bolinder G, Alfredsson L, Englund A, De Faire U. Smokeless tobacco use and increased cardiovascular mortality among swedish construction workers. Am J Public Health. 1994;84(3):399404.

18. Yatsuya H, Folsom AR, Investigators A. Risk of incident cardiovascular disease among users of smokeless tobacco in the Atherosclerosis Risk in Communities (ARIC) study. $\mathrm{Am} J$ Epidemiol. 2010;172(5):600-605. doi:10.1093/aje/kwq191

19. Henley SJ, Thun MJ, Connell C, Calle EE. Two large prospective studies of mortality among men who use snuff or chewing tobacco (United States). Cancer Causes Control. 2005;16(4):347-358. doi:10.1007/s10552-004-5519-6

20. Boffetta P, Straif K. Use of smokeless tobacco and risk of myocardial infarction and stroke: systematic review with meta-analysis. $B M J$. 2009;339:b3060. doi:10.1136/bmj.b2651 
21. Teo KK, Ounpuu S, Hawken S, et al. Tobacco use and risk of myocardial infarction in 52 countries in the INTERHEART study: a case-control study. Lancet. 2006;368:647-658. doi:10.1016/S01406736(06)69249-0

22. Arefalk G, Hambraeus K, Lind L, Michaelsson K, Lindahl B, Sundstrom J. Discontinuation of smokeless tobacco and mortality risk after myocardial infarction. Circulation. 2014;130(4):325-332. doi:10.1161/CIRCULATIONAHA.113.007252

23. Hiler M, Breland A, Spindle T, et al. Electronic cigarette user plasma nicotine concentration, puff topography, heart rate, and subjective effects: influence of liquid nicotine concentration and user experience. Exp Clin Psychopharmacol. 2017;25(5):380-392. doi:10.1037/ pha0000140

24. Talih S, Balhas Z, Eissenberg T, et al. Effects of user puff topography, device voltage, and liquid nicotine concentration on electronic cigarette nicotine yield: measurements and model predictions. Nicotine Tob Res. 2015;17(2):150-157. doi:10.1093/ntr/ntu174

25. Vlachopoulos C, Ioakeimidis N, Abdelrasoul M, et al. Electronic cigarette smoking increases aortic stiffness and blood pressure in young smokers. J Am Coll Cardiol. 2016;67(23):2802-2803. doi:10.1016/j.jacc.2016.03.569

26. McNeil A, Brose LS, Calder R, Hitchman SC, Hajek P, McRobbie H. E-cigarettes: an evidence update. A report commissioned by public health England. A report commissioned by Public Health England 2015 .

27. Goel R, Durand E, Trushin N, et al. Highly reactive free radicals in electronic cigarette aerosols. Chem Res Toxicol. 2015;28(9):16751677. doi:10.1021/acs.chemrestox.5b00220

28. Libby P, Nahrendorf M, Swirski FK. Leukocytes link local and systemic inflammation in ischemic cardiovascular disease: an expanded "cardiovascular continuum". J Am Coll Cardiol. 2016;67 (9):1091-1103. doi:10.1016/j.jacc.2015.12.048

29. Boas Z, Gupta P, Moheimani RS, et al. Activation of the "splenocardiac axis" by electronic and tobacco cigarettes in otherwise healthy young adults. Physiol Rep. 2017;5(17). doi:10.14814/ phy2.13262

30. Shiels MS, Katki HA, Freedman ND, et al. Cigarette smoking and variations in systemic immune and inflammation markers. J Natl Cancer Inst. 2014;106(11). doi:10.1093/jnci/dju061

31. Vardavas CI, Anagnostopoulos N, Kougias M, Evangelopoulou V, Connolly GN, Behrakis PK. Short-term pulmonary effects of using an electronic cigarette: impact on respiratory flow resistance, impedance, and exhaled nitric oxide. Chest. 2012;141(6):1400-1406. doi:10.1378/chest.11-2443

32. Shields PG, Berman M, Brasky TM, et al. A review of pulmonary toxicity of electronic cigarettes in the context of smoking: a focus on inflammation. Cancer Epidemiol Biomarkers Prev. 2017;26(8):11751191. doi:10.1158/1055-9965.EPI-17-0358

33. Flouris AD, Poulianiti KP, Chorti MS, et al. Acute effects of electronic and tobacco cigarette smoking on complete blood count. Food Chem Toxicol. 2012;50(10):3600-3603. doi:10.1016/ j.fct.2012.07.025

34. Carnevale R, Sciarretta S, Violi F, et al. Acute impact of tobacco vs electronic cigarette smoking on oxidative stress and vascular function. Chest. 2016;150(3):606-612. doi:10.1016/j.chest.2 016.04 .012

35. Moheimani RS, Bhetraratana M, Yin F, et al. Increased cardiac sympathetic activity and oxidative stress in habitual electronic cigarette users: implications for cardiovascular risk. JAMA Cardiol. 2017;2(3):278-284. doi:10.1001/jamacardio.2016.5303

36. Mastrangeli S, Carnevale R, Cavarretta E, et al. Predictors of oxidative stress and vascular function in an experimental study of tobacco versus electronic cigarettes: a post hoc analysis of the SUR-VAPES 1 study. Tob Induc Dis. 2018;16(May). doi:10.18332/ tid/89975
37. Heiss C. Electronic cigarettes increase EPCs. Atherosclerosis. 2016;255:119-121. doi:10.1016/j.atherosclerosis.2016.10.033

38. Antoniewicz L, Bosson JA, Kuhl J, et al. Electronic cigarettes increase endothelial progenitor cells in the blood of healthy volunteers. Atherosclerosis. 2016;255:179-185. doi:10.1016/j.atheros clerosis.2016.09.064

39. Chaumont M, de Becker B, Zaher W, et al. Differential effects of Ecigarette on microvascular endothelial function, arterial stiffness and oxidative stress: a randomized crossover trial. Sci Rep. 2018;8 (1):10378. doi:10.1038/s41598-018-28723-0

40. Vlachopoulos C, Aznaouridis K, Stefanadis C. Prediction of cardiovascular events and all-cause mortality with arterial stiffness: a systematic review and meta-analysis. $J$ Am Coll Cardiol. 2010;55 (13):1318-1327. doi:10.1016/j.jacc.2009.10.061

41. Szołtysek-Bołdys I, Sobczak A, Zielińska-Danch W, Bartoń A, Koszowski B, Kośmider L. Influence of inhaled nicotine source on arterial stiffness. Przegl Lek. 2014;71(11):572-575.

42. Hom S, Chen L, Wang T, Ghebrehiwet B, Yin W, Rubenstein DA. Platelet activation, adhesion, inflammation, and aggregation potential are altered in the presence of electronic cigarette extracts of variable nicotine concentrations. Platelets. 2016;27(7):694-702. doi:10.3109/ 09537104.2016.1158403

43. Nocella C, Biondi-Zoccai G, Sciarretta S, et al. Impact of tobacco versus electronic cigarette smoking on platelet function. $\mathrm{Am} \mathrm{J}$ Cardiol. 2018;122(9):1477-1481. doi:10.1016/j.amjcard.2018.07.029

44. Biondi-Zoccai G, Sciarretta S, Bullen C, et al. Acute effects of heat-notburn, electronic vaping, and traditional tobacco combustion cigarettes: the Sapienza University of Rome-vascular assessment of proatherosclerotic effects of smoking (SUR - VAPES) 2 randomized trial. $J$ Am Heart Assoc. 2019;8(6):e010455. doi:10.1161/JAHA.118.010455

45. Yan XS, D'Ruiz C. Effects of using electronic cigarettes on nicotine delivery and cardiovascular function in comparison with regular cigarettes. Regul Toxicol Pharmacol. 2015;71(1):24-34. doi:10.1016/j.yrtph.2014.11.004

46. Franzen KF, Willig J, Cayo Talavera S, et al. E-cigarettes and cigarettes worsen peripheral and central hemodynamics as well as arterial siffness: a randomized, double-blinded pilot study. Vascular Med. 2018;23(5):419-425. doi:10.1177/1358863X18779694

47. Farsalinos K, Cibella F, Caponnetto P, et al. Effect of continuous smoking reduction and abstinence on blood pressure and heart rate in smokers switching to electronic cigarettes. Intern Emerg Med. 2016;11(1):85-94. doi:10.1007/s11739-015-1361-y

48. Farsalinos KE, Tsiapras D, Kyrzopoulos S, Savvopoulou M, Voudris $\mathrm{V}$. Acute effects of using an electronic nicotine-delivery device (electronic cigarette) on myocardial function: comparison with the effects of regular cigarettes. BMC Cardiovasc Disord. 2014;14(78). doi:10.1186/1471-2261-14-78

49. Moheimani RS, Bhetraratana M, Peters KM, et al. Sympathomimetic effects of acute E-cigarette use: role of nicotine and non-nicotine constituents. J Am Heart Assoc. 2017;6(9). doi:10.1161/ JAHA.117.006579

50. Alzahrani T, Pena I, Temesgen N, Glantz SA. Association between electronic cigarette use and myocardial infarction. Am J Prev Med. 2018;55(4):455-461. doi:10.1016/j.amepre.2018.05.004

51. Middlekauff HR, Gornbein J. Association of electronic cigarette use with myocardial infarction: persistent uncertainty. Am J Prev Med. 2019;56(1):159-160. doi:10.1016/j.amepre.2018.06.007

52. Adkison SE, O'Connor RJ, Bansal-Travers M, et al. Electronic nicotine delivery systems: international tobacco control four-country survey. Am J Prev Med. 2013;44(3):207-215. doi:10.1016/j.amepre.2012.10.018

53. Action on smoking and health (ASH) survey group. ASH factsheet: use of e-cigarettes (vapourisers) among adults in Great Britain; September, 2018. Available from: http://ash.org.uk/information-andresources/fact-sheets/use-of-e-cigarettes-among-adults-in-great-brit ain-2017/. Accessed January 24, 2019. 
54. Bullen C, Howe C, Laugesen $\mathrm{M}$, et al. Electronic cigarettes for smoking cessation: a randomised controlled trial. Lancet. 2013;382 (9905):1629-1637. doi:10.1016/S0140-6736(13)61842-5

55. Caponnetto P, Campagna D, Cibella F, et al. EffiCiency and safety of an eLectronic cigAreTte (ECLAT) as tobacco cigarettes substitute: a prospective 12-month randomized control design study. PLoS One. 2013;8(6):e66317. doi:10.1371/journal.pone.0066317

56. Adriaens K, Van Gucht D, Declerck P, Baeyens F. Effectiveness of the electronic cigarette: an eight-week Flemish study with six-month follow-up on smoking reduction, craving and experienced benefits and complaints. Int J Environ Res Public Health. 2014;11(11):1122011248. doi:10.3390/ijerph111111220

57. Hajek P, Phillips-Waller A, Przulj D, et al. A randomized trial of Ecigarettes versus nicotine-replacement therapy. $N$ Engl J Med. 2019;380:629-637. doi:10.1056/NEJMoa1808779

58. Hartmann-Boyce J, McRobbie H, Bullen C, Begh R, Stead LF, Hajek P. Electronic cigarettes for smoking cessation. Cochrane Database Syst Rev. 2016;9:CD010216.

59. Beard E, West R, Michie S, Brown J. Association between electronic cigarette use and changes in quit attempts, success of quit attempts, use of smoking cessation pharmacotherapy, and use of stop smoking services in England: time series analysis of population trends. Bmj. 2016;354:i4645. doi:10.1136/bmj.i4645

60. Ghosh S, Drummond MB. Electronic cigarettes as smoking cessation tool: are we there? Curr Opin Pulm Med. 2017;23(2):111-116. doi:10.1097/MCP.0000000000000348

61. Brose LS, Hitchman SC, Brown J, West R, McNeill A. Is the use of electronic cigarettes while smoking associated with smoking cessation attempts, cessation and reduced cigarette consumption? A survey with a 1-year follow-up. Addiction. 2015;110(7):1160-1168. doi:10.1111/add.12917

62. Hitchman SC, Brose LS, Brown J, Robson D, McNeill A. Associations between E-cigarette type, frequency of use, and quitting smoking: findings from a longitudinal online panel survey in great Britain. Nicotine Tob Res. 2015;17(10):1187-1194. doi:10.1093/ntr/ntv078
63. Pope CA 3rd, Burnett RT, Turner MC, et al. Lung cancer and cardiovascular disease mortality associated with ambient air pollution and cigarette smoke: shape of the exposure-response relationships. Environ Health Perspect. 2011;119(11):1616-1621. doi:10.1289/ ehp.1103639

64. Kalkhoran S, Glantz SA. E-cigarettes and smoking cessation in realworld and clinical settings: a systematic review and meta-analysis. Lancet Respir Med. 2016;4(2):116-128. doi:10.1016/S2213-2600(15) 00521-4

65. Miech R, Johnston L, O'Malley PM, Bachman JG, Patrick ME. Adolescent vaping and nicotine use in 2017-2018 - U.S. national estimates. $N$ Engl J Med. 2019;380(2):192-193. doi:10.1056/ NEJMc1814130

66. Levy DT, Warner KE, Cummings KM, et al. Examining the relationship of vaping to smoking initiation among US youth and young adults: a reality check. Tob Control. 2018. doi:10.1136/tobaccocontrol-2018-054446

67. Ip M, Middlekauff HR. Noncigarette tobacco products-gateway or diversion? JAMA Pediatr. 2018;172(8):784. doi:10.1001/ jamapediatrics.2018.1073

68. Office of the Surgeon General. Surgeon General's Advisory on ECigarette Use among Youth. 2018. Available from: e-cigarettes.surgeongeneral.gov/documents/surgeon-generals-advisory-on-e-cigarette-use-among-youth-2018.pdf. Accessed June 13, 2019.

69. National Youth Tobacco Survey (NYTS) [webpage on the Internet]. Atlanta, GA: Centers for Disease Control and Prevention; 2018 [updated February 28, 2019]. Available from: https://www.cdc.gov/ tobacco/data_statistics/surveys/nyts/index.htm. Accessed June 13, 2019.

70. Academy of Sciences, Engineering, and Medicine. Public Health Consequences of E-Cigarettes. Washington, DC: The National Academies Press; 2018.

\section{Publish your work in this journal}

Vascular Health and Risk Management is an international, peerreviewed journal of therapeutics and risk management, focusing on concise rapid reporting of clinical studies on the processes involved in the maintenance of vascular health; the monitoring, prevention and treatment of vascular disease and its sequelae; and the involvement of metabolic disorders, particularly diabetes. This journal is indexed on PubMed Central and MedLine. The manuscript management system is completely online and includes a very quick and fair peerreview system, which is all easy to use. Visit http://www.dovepress com/testimonials.php to read real quotes from published authors. 